\title{
An improved algorithm for retrieving the fine-mode fraction of aerosol optical thickness, Part 1: Algorithm development
}

\author{
Xing Yan ${ }^{\text {a, b }}$, Zhanqing $\mathrm{Li}^{\text {b, }{ }^{*} \text {, Wenzhong Shi }}{ }^{\text {a }}$, Nana Luo ${ }^{\mathrm{d}}$, Taixia $\mathrm{Wu}{ }^{\mathrm{e}}$, \\ Wenji Zhao ${ }^{\mathrm{f}}$
}

a Department of Land Surveying and Geo-Informatics, The Hong Kong Polytechnic University, Hong Kong, China

b Department of Atmospheric and Oceanic Science, and Earth System Science Interdisciplinary Center, University of Maryland, College Park, Maryland, USA c State Key Laboratory of Earth Surface Processes and Resource Ecology and College of Global Change and Earth System Science, Beijing Normal University, Beijing, China

d Department of Geography, San Diego State University, 5500 Campanile Dr., San Diego, USA

e Institute of Remote Sensing and Digital Earth, Chinese Academy of Sciences, Beijing, China

f College of Resource Environment and Tourism, Capital Normal University, Beijing, China

*Corresponding author:

Zhanqing $\mathrm{Li}$

Department of Atmospheric \& Oceanic Science \& Earth System Science Interdisciplinary Center

5825 University Research Court, \# 4001, College Park, MD20740-3823

Phone: (301) 405-6699

Fax: (301) 405-8468

Email: zli@atmos.umd.edu 


\begin{abstract}
The fine-mode fraction (FMF) can be a useful tool to separate natural aerosols from man-made aerosols and to assist in estimating surface concentrations of particulate matter with a diameter less than $2.5 \mu \mathrm{m}$. A LookUp Table-based Spectral Deconvolution Algorithm (LUT-SDA) was developed here for satellite-based applications using data such as MODerate resolution Imaging Spectroradiometer (MODIS) measurements. This method was validated against ground-based FMF retrievals from the Aerosol Robotic Network (AERONET). The LUT-SDA was then applied to two MODIS-retrieved aerosol optical thickness (AOT) products for the period of December 2013 to July 2015: the MODIS Collection 6 (C6) Dark Target (DT) AOT product and the simplified high-resolution MODIS Aerosol Retrieval Algorithm (SARA) AOT product. In comparison with the MODIS C6 FMF product in three study areas (Beijing, Hong Kong, and Osaka), FMFs estimated by the LUT-SDA agreed more closely with those retrieved from the AERONET with a very low bias. Eighty percent of the FMF values fell within the expected error range of \pm 0.4 . The root mean square error (RMSE) was 0.168 with few anomalous values, whereas the RMSE for the MODIS FMF was 0.340 with more anomalous values. The LUT-SDA FMF estimated using SARA AOT data conveys more detailed information on urban pollution than that from MODIS C6 DT AOT data. As a demonstration, the seasonally-averaged spatial distribution of the FMF in Beijing was obtained from the LUT-SDA applied to SARA AOT data and compared with that of the AERONET-retrieved FMF. Their seasonal trends agreed well.
\end{abstract}

Keywords: aerosol fine-mode fraction; MODIS; AOT; $\mathrm{PM}_{2.5}$ 


\section{Introduction}

Atmospheric aerosols play a very important role in Earth's energy balance and on climate change (Kaufman et al., 2002; Ramanathan et al., 2007). They can also have an adverse effect on human health (Pope et al., 2002). At present, our understanding of aerosol size distributions from a spatial perspective is still limited.

The fine-mode fraction (FMF) is an important physical property of aerosols that can be used to separate natural aerosols from man-made aerosols (Bellouin et al., 2005). Like AOT, the aerosol FMF can be estimated from either space-borne AOT observations such as those from the MODerate resolution Imaging Spectroradiometer (MODIS) or from the ground-based AOT measurements from the AERONET. Levy et al. (2010) reported that the MODIS-retrieved FMF over land is still experimental and highly uncertain. This is because satellite AOT retrievals have to differentiate signals from aerosols and the land surface whose reflectance can be substantial (Diner et al., 2005; Hauser et al., 2005; Mishchenko and Geogdzhayev, 2007; Li et al., 2009; Kokhanovsky et al., 2010; Lee and Chung, 2013). Because of this, the FMF over land is much less accurate than over oceans. However, the AERONET FMF is based on the Spectral Deconvolution Algorithm (SDA), which uses solar extinction data obtained directly from solar measurements. As such, it is only slightly influenced by surface reflectance and is almost as accurate over oceans as over land (O'Neill et al., 2001, 2003). Gasso and O’Neill (2006) showed a good correlation between the fine-mode AOT from a sunphotometer and airborne in situ measurements using the SDA. However, the AERONET has a much smaller spatial coverage than does the MODIS.

The FMF may help estimate surface concentrations of particulate matter (PM) with a diameter less than $2.5 \mu \mathrm{m}\left(\mathrm{PM}_{2.5}\right)$, as it pertains to the contributions of smaller and larger particles to the AOT. Many studies have attempted to develop statistical models to estimate $\mathrm{PM}_{2.5}$ from AOT. Di Nicolantonio et al. (2007) reported a sound correlation between the fine-mode AOT and $\mathrm{PM}_{2.5}$ with a correlation coefficient reaching 0.74. Zhang and $\mathrm{Li}$ (2013) found that the relationship between fine-mode 
AOT and $\mathrm{PM}_{2.5}$ was stronger than that between AOT and $\mathrm{PM}_{2.5}$ under hazy weather conditions in winter. Zhang and $\mathrm{Li}$ (2015) derived a relation involving the FMF and the columnar volume-to-extinction ratio of fine particulates based on eight AERONET sites, and applied it to estimate $\mathrm{PM}_{2.5}$ from MODIS measurements. However, Levy et al. (2007) revealed that the MODIS FMF had little correlation with the AERONET FMF. This may be because AERONET and MODIS FMFs were derived using different methods. AERONET assumes a fine mode and coarse mode with no overlap, whereas MODIS uses bimodal lognormal models that may be overlapped to a certain extent (Kampe, 2008). Also, the MODIS FMF is not determined as a continuous variable, but as 11 discrete values from 0 to 1 . Jethva et al. (2010) compared the MODIS FMF with the AERONET FMF and found that the root mean square difference between the two was 0.61 (number of samples, $\mathrm{N}=651$ ).

As shown by O'Neill et al. (2001), the SDA was developed as a simple and efficient method for determining the fractions of fine and coarse modes from spectral AOTs. They showed that the Ångström exponent (AE) of fine-mode aerosols can be extracted directly from the first and second order spectral derivatives of AOT, which means that values of AOT at a minimum of three wavelengths are needed. However, most of the current satellite aerosol retrieval products provide AOT at only the blue and red bands (Zha et al., 2011; Luo et al., 2015), e.g., the retrieval products derived from the DT method (Levy et al., 2007) and the minimum reflectance technique (Wong et al., 2011). If AOT is available at only two wavelengths, the AE can be calculated using the Volz method (Soni et al., 2011), but the AE derivative cannot be obtained from a second-order polynomial fit. Thus, an FMF retrieval method based on AOT at two bands needs to be developed.

The main objective of this study is to improve the spectral decomposition method so that it can estimate the FMF based on AOT at two wavelengths following a LookUp Table-based SDA (LUT-SDA) method for satellite applications. The method is demonstrated using ground-based AERONET measurements made in Beijing, Hong Kong, and Osaka. We will then use the derived FMF to estimate $\mathrm{PM}_{2.5}$, the subject covered in Part II of this study. 


\section{Data and methods}

\subsection{Study area}

For the sake of demonstration on an urban scale, we chose Beijing, Hong Kong, Osaka, and their surrounding areas as our test area because of their distinctly different environments and differing meteorological conditions (Figure 1). Beijing is the most polluted and driest among the three sites. Hong Kong is a coastal city with low to moderate levels of pollution and a marine climate. Osaka is in the centre of Japan and is the largest commercial and industrial city after Tokyo (Sasaki and Sakamoto, 2005). Because AOT retrievals depend critically on surface albedo and aerosol single scattering albedo, the retrievals from each of these regions are different, offering an opportunity to test the spatial adaptability of the LUT-SDA method.
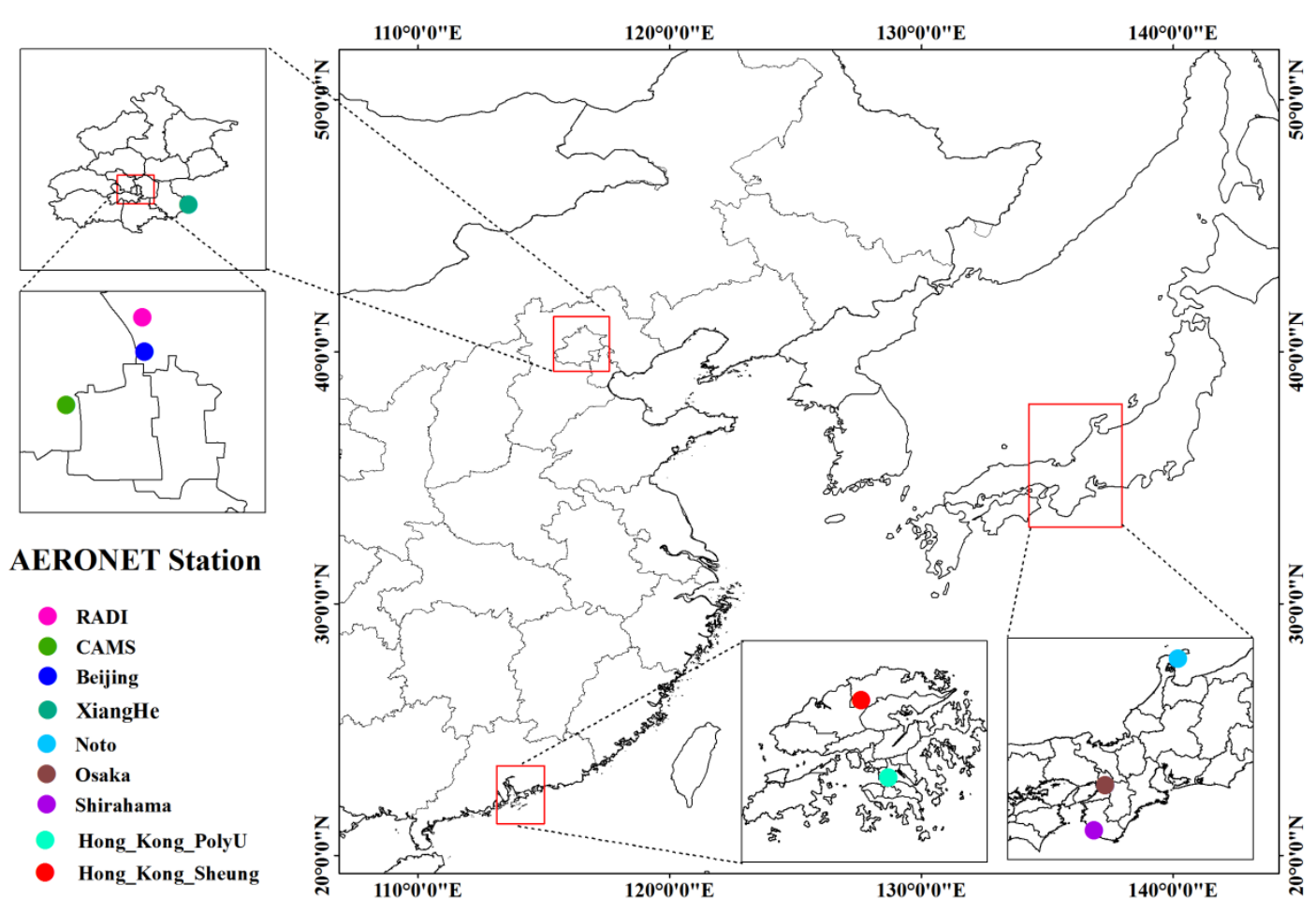

Figure 1. The Beijing, Hong Kong, and Osaka study areas (outlined in red). The locations of the nine AERONET sites used in the study are: Beijing $\left(39.98^{\circ} \mathrm{N}\right.$, $\left.116.38^{\circ} \mathrm{E}\right)$, CAMS $\left(39.93^{\circ} \mathrm{N}, 116.32^{\circ} \mathrm{E}\right)$, RADI $\left(40.01^{\circ} \mathrm{N}, 116.38^{\circ} \mathrm{E}\right)$, XiangHe $\left(39.75^{\circ} \mathrm{N}, 116.96^{\circ} \mathrm{E}\right)$, Noto $\left(37.33^{\circ} \mathrm{N}, 137.14^{\circ} \mathrm{E}\right)$, Osaka $\left(34.65^{\circ} \mathrm{N}, 135.59^{\circ} \mathrm{E}\right)$, 
Shirahama $\left(33.69^{\circ} \mathrm{N}, 135.36^{\circ} \mathrm{E}\right)$, Hong_Kong_Polyu $\left(22.30^{\circ} \mathrm{N}, 114.18^{\circ} \mathrm{E}\right)$, and Hong_Kong_Sheung $\left(22.48^{\circ} \mathrm{N}, 114.12^{\circ} \mathrm{E}\right)$.

\subsection{The LUT- Spectral Decomposition Algorithm (SDA)}

The LUT-SDA proposed here uses an LUT for retrieving the FMF from satellite-derived AOT and AE. To build an LUT, a set of hypothetical FMF $(\eta)$ and AE derivative $\left(\alpha^{\prime}\right)$ values are imported to the SDA calculation along with the satellite-determined $\mathrm{AE}(\alpha)$ for deriving the $\mathrm{AE}$ of fine-mode aerosols $\left(\alpha_{f}\right)$. The incremental interval for $\eta$ is 0.01 with a range from 0 to 1 . The incremental interval for $\alpha^{\prime}$ is 0.001 and its range for a given satellite image will be discussed in section 3.1. The FMF can then be estimated by minimizing $\chi^{2}$ in this LUT. The LUT based on the SDA is described as follows:

A simplified expression for the estimation of $\alpha_{f}$ can be written as (O'Neill et al., 2001):

$\alpha_{f}=\frac{1}{2(1-\mathrm{a})}\left\{\left(\alpha-\alpha_{c}-\frac{\alpha^{\prime}-\alpha_{c}{ }^{\prime}}{\alpha-\alpha_{c}}+\mathrm{b}^{*}\right)+\left[\left(\alpha-\alpha_{c}-\frac{\alpha^{\prime}-\alpha_{c}{ }^{\prime}}{\alpha-\alpha_{c}}+\mathrm{b}^{*}\right)^{2}+4 \mathrm{c}^{*}(1-\mathrm{a})\right]^{1 / 2}\right\}+\alpha_{c}$,

where $\alpha$ is the $\mathrm{AE}$ of the total aerosols, and $\alpha_{f}$ and $\alpha_{c}$ are fine- and coarse-mode AEs, respectively. The parameters $\mathrm{a}, \mathrm{b}^{*}, \mathrm{c}^{*}, \alpha^{\prime}$, and $\alpha_{c}$ can be found in O'Neill (2010) and are also shown in Supplementary Section 1. The parameter $\alpha_{f}$ is calculated as (O’Neill et al., 2001):

$$
\alpha_{f}^{*}=\frac{\alpha-\alpha_{c}}{\eta}+\alpha_{c}
$$

The LUT of the SDA for this study is based on Eq. (1) and Eq. (2), which changes $\eta$ and $\alpha^{\prime}$ with a given step size within a certain range to build the relationship between $\alpha, \alpha_{f}, \alpha^{\prime}$, and $\eta$. Then the difference between $\alpha_{f}$ and $\alpha_{f}^{*}$ is: 


$$
\chi^{2}=\left(\alpha_{f}-\alpha_{f}^{*}\right)^{2}
$$

The LUT-SDA calculation is summarized as follows:

$$
\left.\begin{array}{l}
\left(\eta^{1}, \alpha^{\prime 1}\right)=\min \left(\chi^{2}\right) \\
\alpha_{f}{ }^{1}=\frac{\alpha-\alpha_{c}}{\eta^{1}}+\alpha_{c}
\end{array}\right\}
$$

where $\eta^{1}, \alpha^{1}$, and $\alpha_{f}{ }^{1}$ are uncorrected estimates of $\eta, \alpha^{\prime}$, and $\alpha_{f}$. Finally, through the $\alpha^{\prime}$ bias error correction (Supplementary Section 2) and the mean of extreme (MOE) modification (Supplementary Section 3, which is the same as in the SDA Version 4.1), $\eta$ can be obtained.

\subsection{AOT and AE data}

Two sets of AOT and AE retrievals are used in this study: one set is from the MODIS Collection 6 (MODIS C6) aerosol product and the other set is derived from the Simplified high-resolution MODIS Aerosol Retrieval Algorithm (SARA). The "Dark Target" (DT) algorithm-based AOTs at the blue and red bands are extracted from the MODIS C6 aerosol product. We use the 10-km resolution MODIS C6 AOT products to retrieve the FMF due to its higher accuracy relative to the 3-km resolution AOT products (Remer et al., 2013; Munchak et al., 2013; Yan et al., 2016). The AE is then calculated using AOT at the two wavelengths:

$$
\alpha=-\frac{\ln \left(\frac{\tau_{1}}{\tau_{2}}\right)}{\ln \left(\frac{\lambda_{2}}{\lambda_{1}}\right)},
$$

where $\lambda_{1}$ and $\lambda_{2}$ are the different wavelengths in $\mu \mathrm{m}(0.47$ and $0.66 \mu \mathrm{m}$ in this study), and $\tau_{1}$ and $\tau_{2}$ are the AOT at $\lambda_{1}$ and $\lambda_{2}$, respectively.

The C6 product still uses the VISvs2.1 surface reflectance parameterization with a shortwave-infrared normalized difference vegetation index dependence (Levy et al., 2013), which is described by Levy et al. (2007). 
The spatial resolution of the MODIS C6 aerosol product $(10 \mathrm{~km})$ is too coarse for urban-scale studies, so this study uses a higher resolution AOT (500 m) for the retrieval of the FMF. Bilal et al. (2013) proposed the SARA method for AOT retrievals, which was applied and validated using data from Beijing (Bilal et al., 2014). The AOT from the SARA is calculated as

$$
\tau_{a}=\frac{4 \mu_{s} \mu_{v}}{\omega_{0} P_{a}}\left[\rho_{\text {TOA }}-\rho_{\text {Ray }}-\frac{e^{-\left(\tau_{R}+\tau_{a}\right) / \mu_{s}} e^{-\left(\tau_{R}+\tau_{a}\right) / \mu_{v}} \rho_{s}}{1-\rho_{s}\left(0.92 \tau_{R}+(1-\mathrm{g}) \tau_{a}\right) \exp \left[-\left(\tau_{R}+\tau_{a}\right)\right]}\right], \text { (6) }
$$

where $\tau_{a}$ is the AOT, $\tau_{R}$ is the Rayleigh optical depth, $\rho_{\text {TоA }}$ is the satellite-measured top of the atmosphere reflectance, $\rho_{\text {Ray }}$ is the Rayleigh reflectance, $\rho_{s}$ is the surface reflectance, $\mu_{s}$ is the cosine of the solar zenith angle, $\mu_{v}$ is the cosine of the sensor zenith angle, $\mathrm{g}$ is the asymmetry factor, $\omega_{0}$ is the single scattering albedo (SSA), and $P_{a}$ is the aerosol scattering phase function. MODIS Terra Level 1B products (MOD02HKM calibrated radiances and MOD03 geolocation data), the MODIS surface reflectance product (MOD09GA, MODIS_Grid_500m_2D), and MODIS C6 aerosol products from December 2013 to July 2015 were used. Data from cloud-free days were extracted from these datasets. The MOD02HKM product $(500 \mathrm{~m})$ was used for obtaining $\rho_{\text {TOA }}$ and the MOD03 product provided satellite and solar angles. Finally, the FMF extracted from the MODIS C6 aerosol product was used for comparison purposes (only the DT method releases an FMF product).

The flowchart describing the LUT-SDA and its comparison with the SDA is shown in Figure 2. 


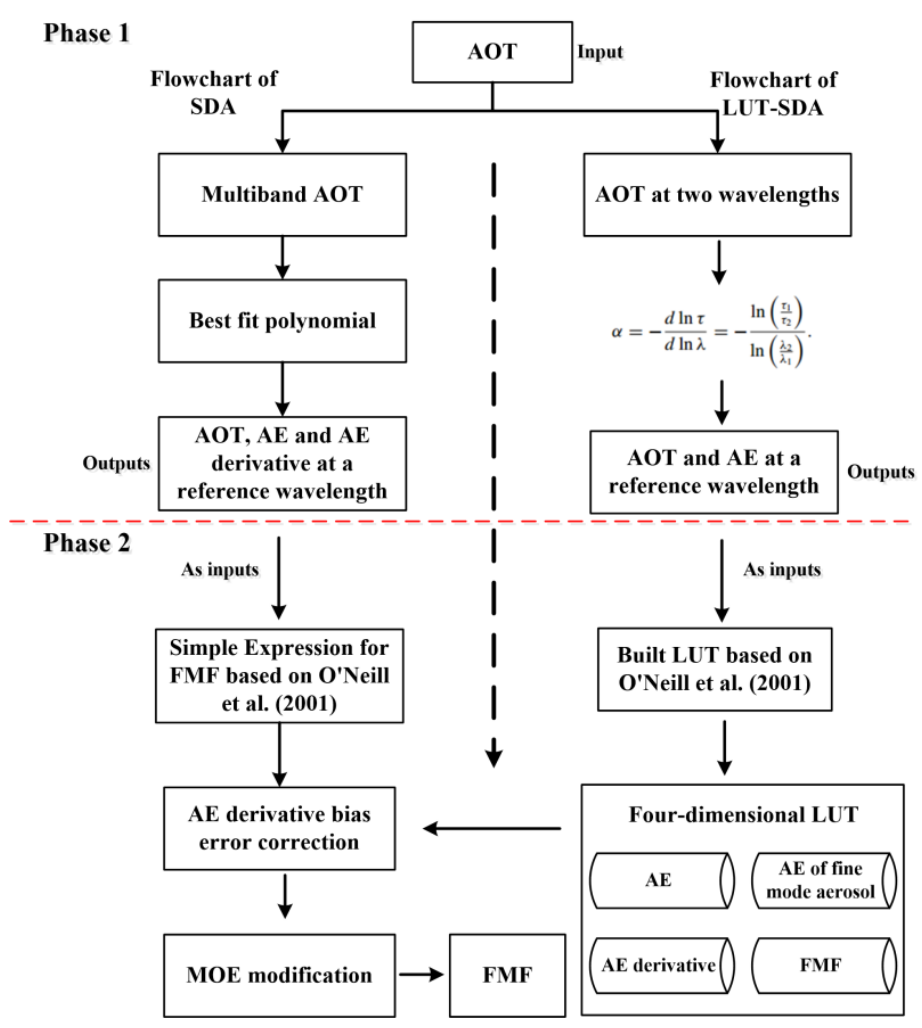

Figure 2. Flowchart describing the SDA and the LUT-SDA.

\subsection{AERONET}

The AERONET is a globally distributed network, which provides multi-wavelength AOT measurements with a high accuracy and an uncertainty less than 0.02 (Holben et al., 2001). In this study, FMF data from nine AERONET stations were used for validation (Figure 1): Beijing (Level 2), CAMS (Level 2), RADI (only Level 1.5 available), XiangHe (Level 2), Noto (Level 2), Osaka (Level 2), Shirahama (Level 2), Hong_Kong_Polyu (Level 2), and Hong_Kong_Sheung (Level 2).

\section{Results and discussion}

\subsection{LUT-SDA and optimal AE derivative for satellite images}

The LUT used in the LUT-SDA based on Eq. (1) and Eq. (2) is shown in Figure 3. Solid lines represent $\eta$ with constant values ( 0.1 to 1 in increments of 0.2 ). 
Dashed lines represent $\alpha^{\prime}$ with constant values (-2 to 2 in increments of 1 ). The dashed lines representing $\alpha^{\prime}$ equal to 1 and 2 are very short and are not visible in the figure. Based on the LUT-SDA, $\alpha$ 'has a great influence on the retrieved FMF. The magnitude of the increment selected to divide the range of $\alpha^{\prime}$ values in the LUT is a key factor in the retrieval of the FMF. A better accuracy in $\alpha^{\prime}$ is achieved as the increment becomes smaller. However, to analyze satellite images, a finer resolution would substantially increase the computational time. Thus, for satellite data, a reliable and computationally less expensive method is needed. An AERONET-based dataset of daily $\alpha^{\prime}$ calculated from the year 2009 to 2012 was generated for different regions (Beijing, Hong Kong, and Osaka). Figure 4 shows histograms of $\alpha^{\prime}$ for these four years. The distributions of $\alpha^{\prime}$ are different in each of the study areas. $\alpha^{\prime}$ is always negative in Beijing (mean $=-0.23)$, while it is positive in Hong Kong $($ mean $=0.65)$ and Osaka (mean $=0.54)$. In general, the daily $\alpha^{\prime}$ ranges from -1.2 to $1.2,-0.6$ to 1.8, and -0.6 to 1.4 in Beijing, Hong Kong, and Osaka, respectively. In addition, all these ranges contain the first and third quartiles of $\alpha^{\prime}$. So to calculate the satellite FMF, the range of $\alpha^{\prime}$ is set to -1.2 to 1.2 for Beijing, -0.6 to 1.8 for Hong Kong, and -0.6 to 1.4 for Osaka with incremental intervals of 0.001 in the LUT. To validate the LUT-SDA performance and to show the differences between the LUT-SDA and the SDA, we used the same AERONET-retrieved AOT (500 nm) and AE data from January to June 2013 as input to calculate the FMF. Figure 5 shows that the LUT-SDA-derived FMF matches the SDA-derived FMF well, which suggests that the LUT-SDA can provide reliable estimates of the FMF. To analyze the impact of the AERONET-based AOT retrieval error on the FMF, the correlation between the errors of the FMF [abs(AERONET FMF - LUT-SDA FMF)] and those of $\alpha^{\prime}$ [abs(AERONET $\alpha^{\prime}$ - LUT-SDA $\left.\alpha^{\prime}\right)$ ] is shown in Figure 6. The FMF error increases as the error in $\alpha^{\prime}$ increases. Because the AOT and AE inputs are the same for each algorithm, the only difference in input is $\alpha^{\prime}$ (Figure 2). As shown in Figure 4, the empirical range of $\alpha^{\prime}$ cannot contain all cases, and the incremental interval of $\alpha^{\prime}$ will also contribute toward the error of the final FMF calculation as shown in Eq. 


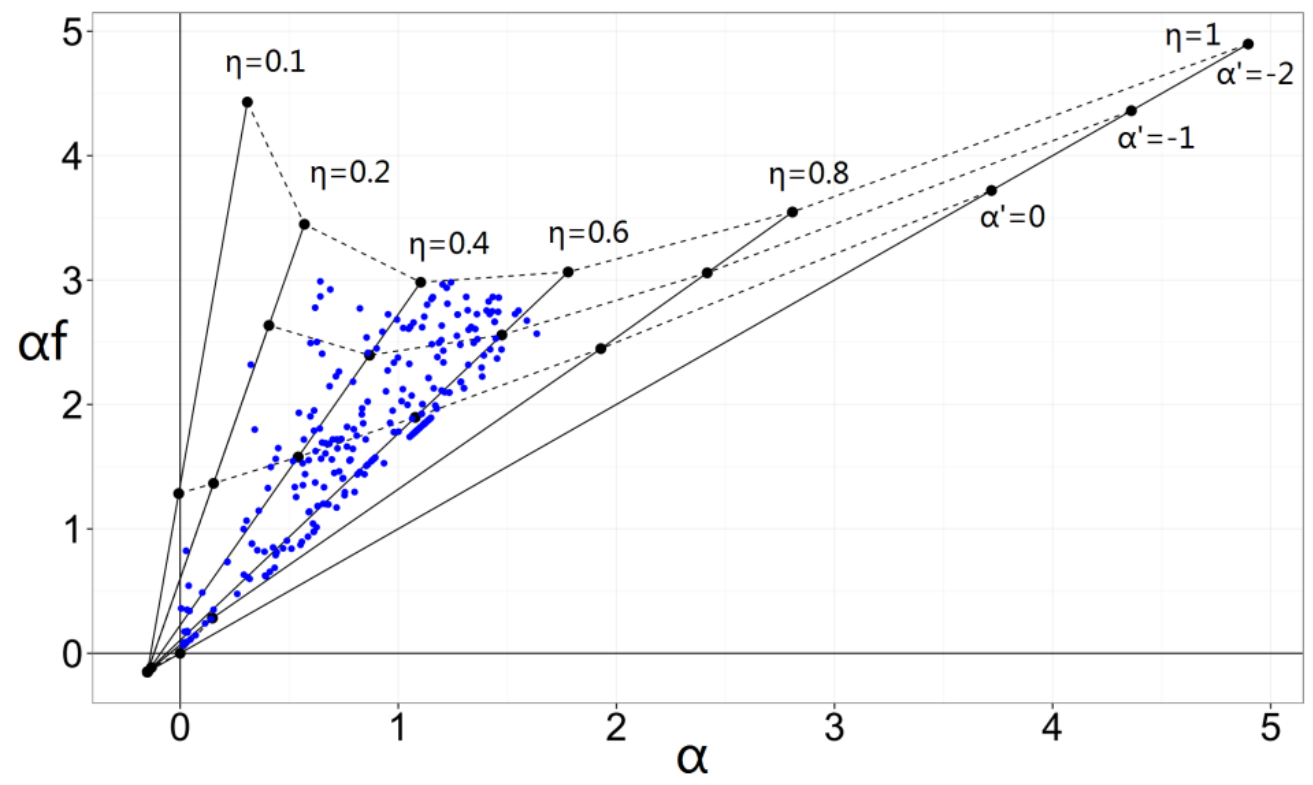

Figure 3. The look-up table used in the LUT-SDA. The blue points are test data from AERONET.
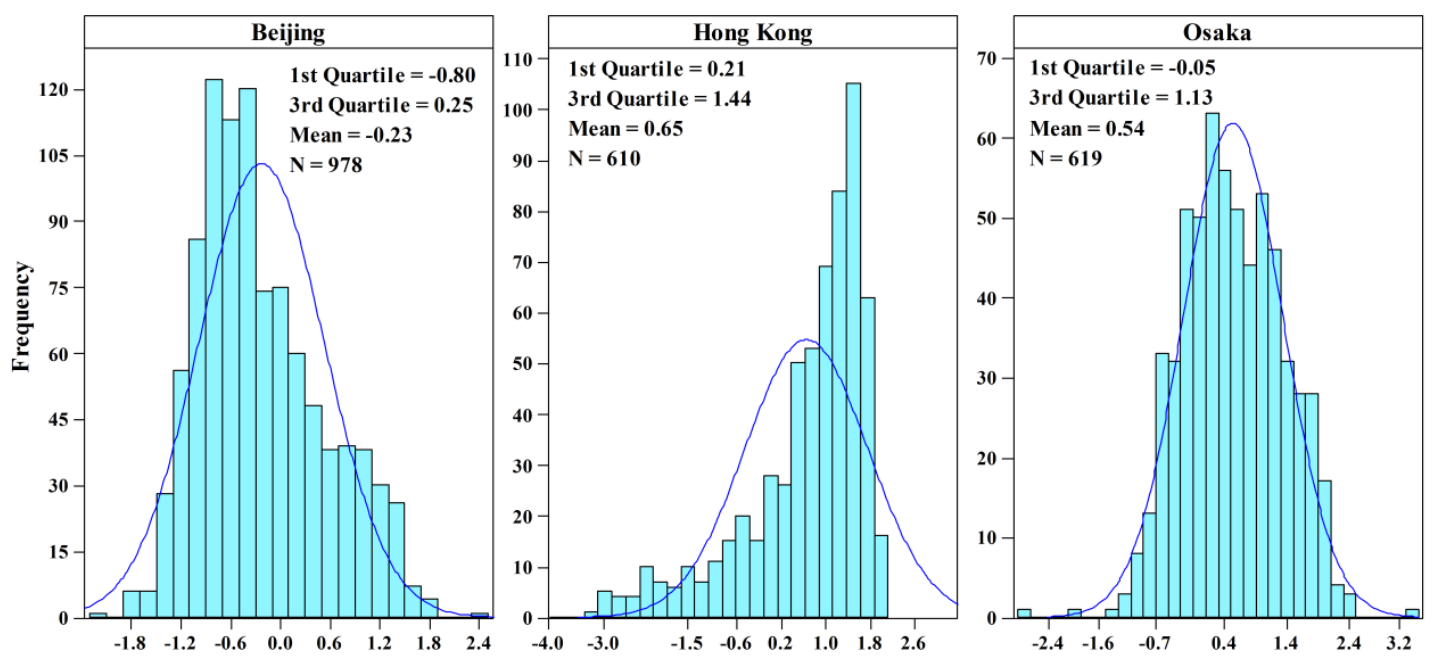

Figure 4. Histograms of $\alpha^{\prime}$ from four years (2009 to 2012) for Beijing, Hong Kong, and Osaka. 


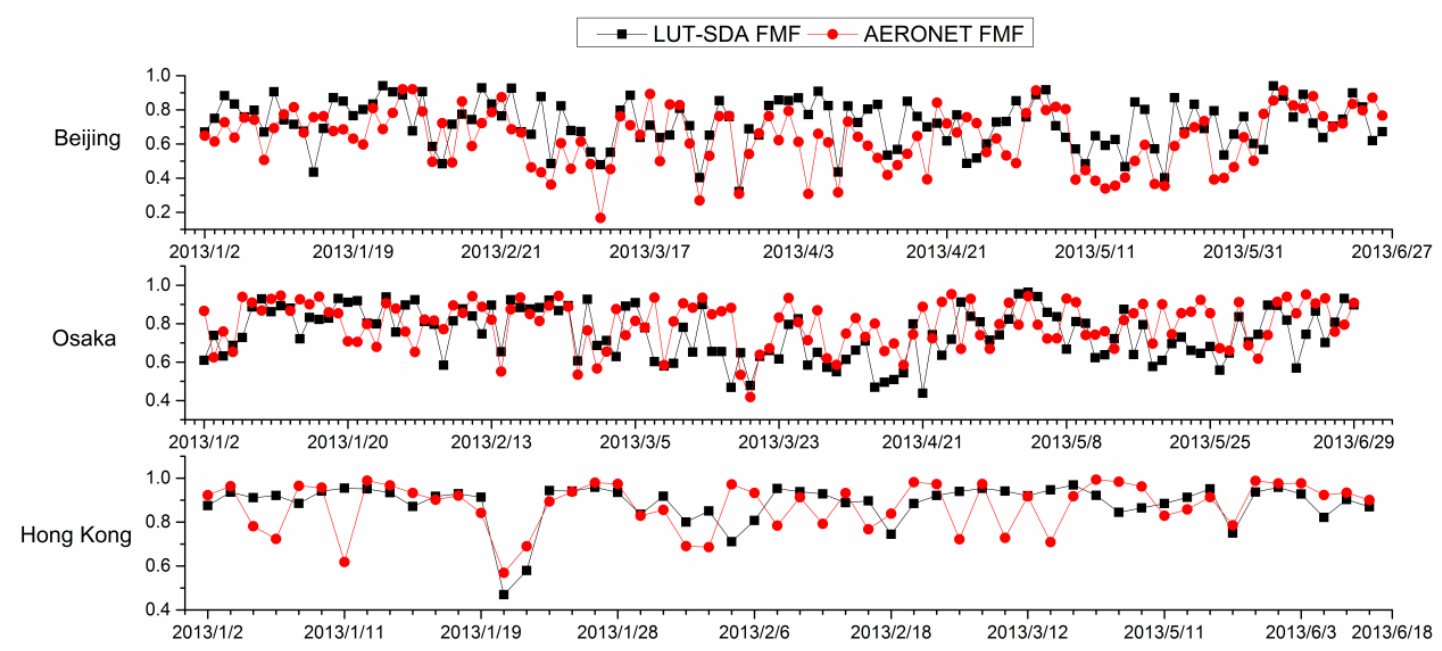

Figure 5. Comparisons of the LUT-SDA-derived FMF (in black) and the AERONET FMF (in red) from January to June 2013 in Beijing, Osaka, and Hong Kong.

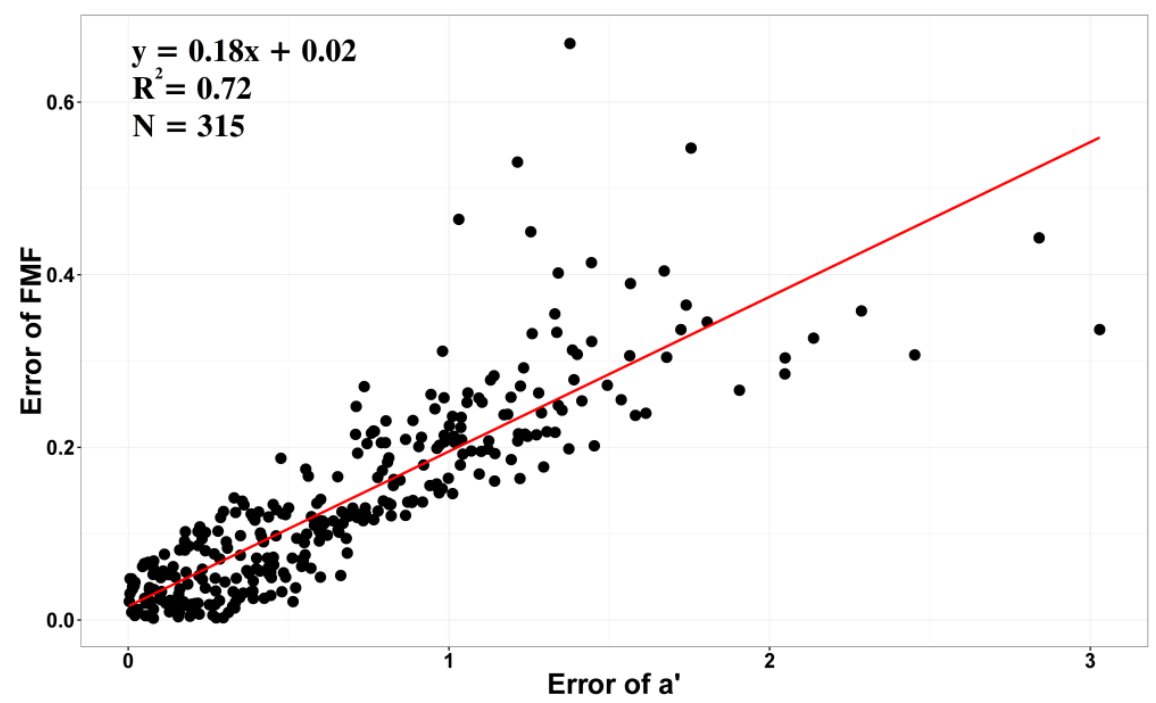

Figure 6. Correlation between the FMF and $\alpha$ 'errors. The red line is the best-fit line through the data points.

\subsection{An application to the MODIS C6 aerosol product}

The LUT-SDA was applied to data extracted from the MODIS C6 aerosol product for Beijing (7 April 2014), Hong Kong (23 March 2014), and Osaka (14 December 2014) so that the performance of the LUT-SDA FMF and comparisons with the MODIS C6 FMF could be examined. Figure 7 shows that the MODIS C6 FMF has nil values in many locations while the LUT-SDA FMF does not. This phenomenon is also seen in other cases, which are shown in supplementary Figures S1-S6. 


\section{LUT-SDA FMF}
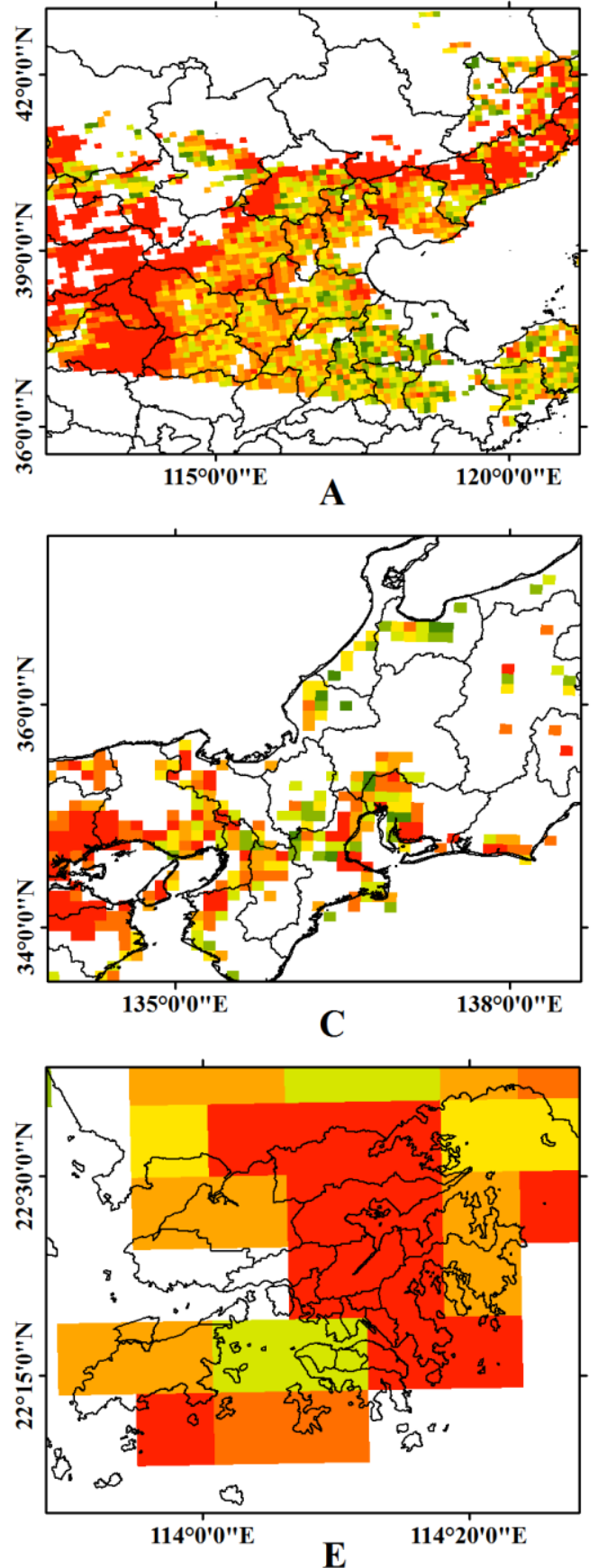

MODIS C6 FMF
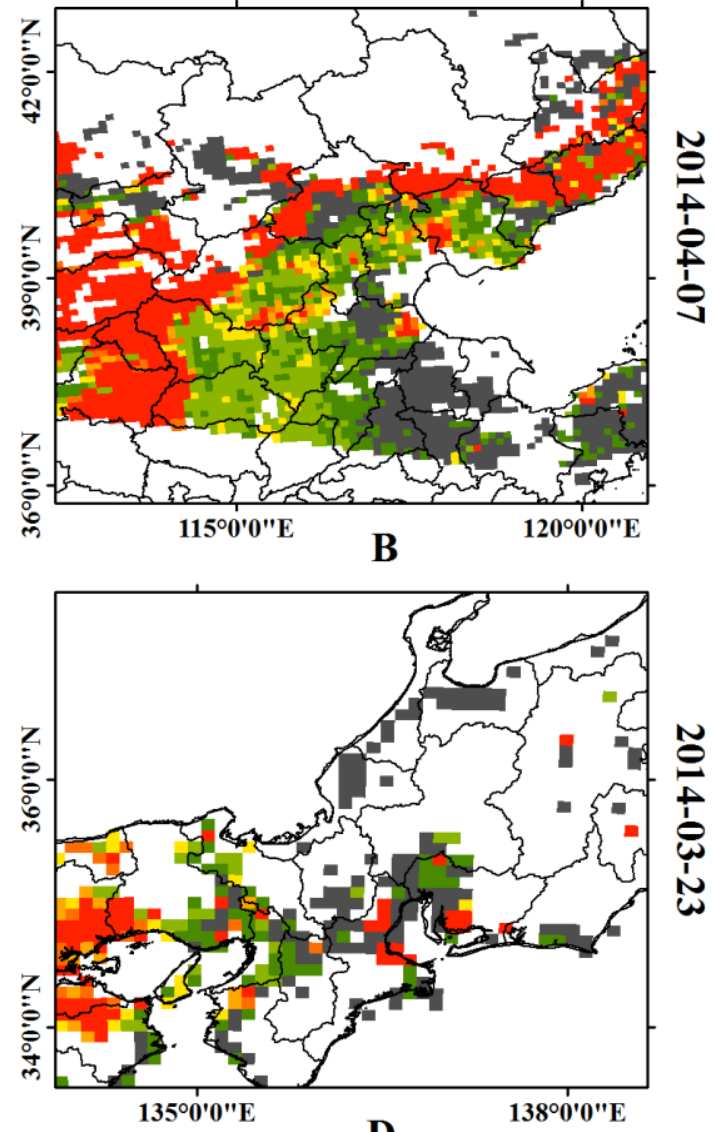

D

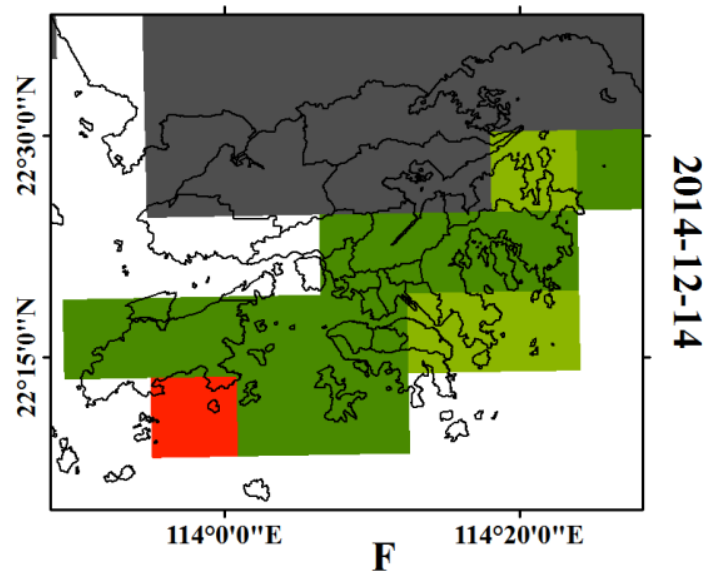

FMF

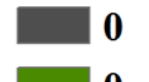

$0.4-0.5$

$0.6-0.7$

$0.8-0.9$

Figure 7. Spatial distributions of the LUT-SDA FMF (left column) and the MODIS C6 FMF (right column) for Beijing (top row), Osaka (middle row), and Hong Kong (bottom row). 
Figure 8 shows the scatterplot of LUT-SDA-derived and MODIS C6 FMFs as a function of AERONET FMF (daily comparisons of data from different AERONET stations are shown in supplementary Figure S7). There are more points concentrated around the 1:1 line, with $80 \%$ of them falling within the expected error (EE) envelope of \pm 0.4 for LUT-SDA FMF. $20 \%$ of the MODIS C6 FMF points fall within the EE envelope, with $76 \%$ of them beyond the EE envelope due to the nil value problem (the histogram shown in supplementary Figure S8). The RMSEare summarized in Table 1. The RMSEs of the LUT-SDA FMF are all less than those of the MODIS C6 FMF at the nine AERONET stations. The mean RMSE of the LUT-SDA FMF at these AERONET stations is 0.168 , which is less than the mean RMSE of the MODIS C6 FMF (0.340).

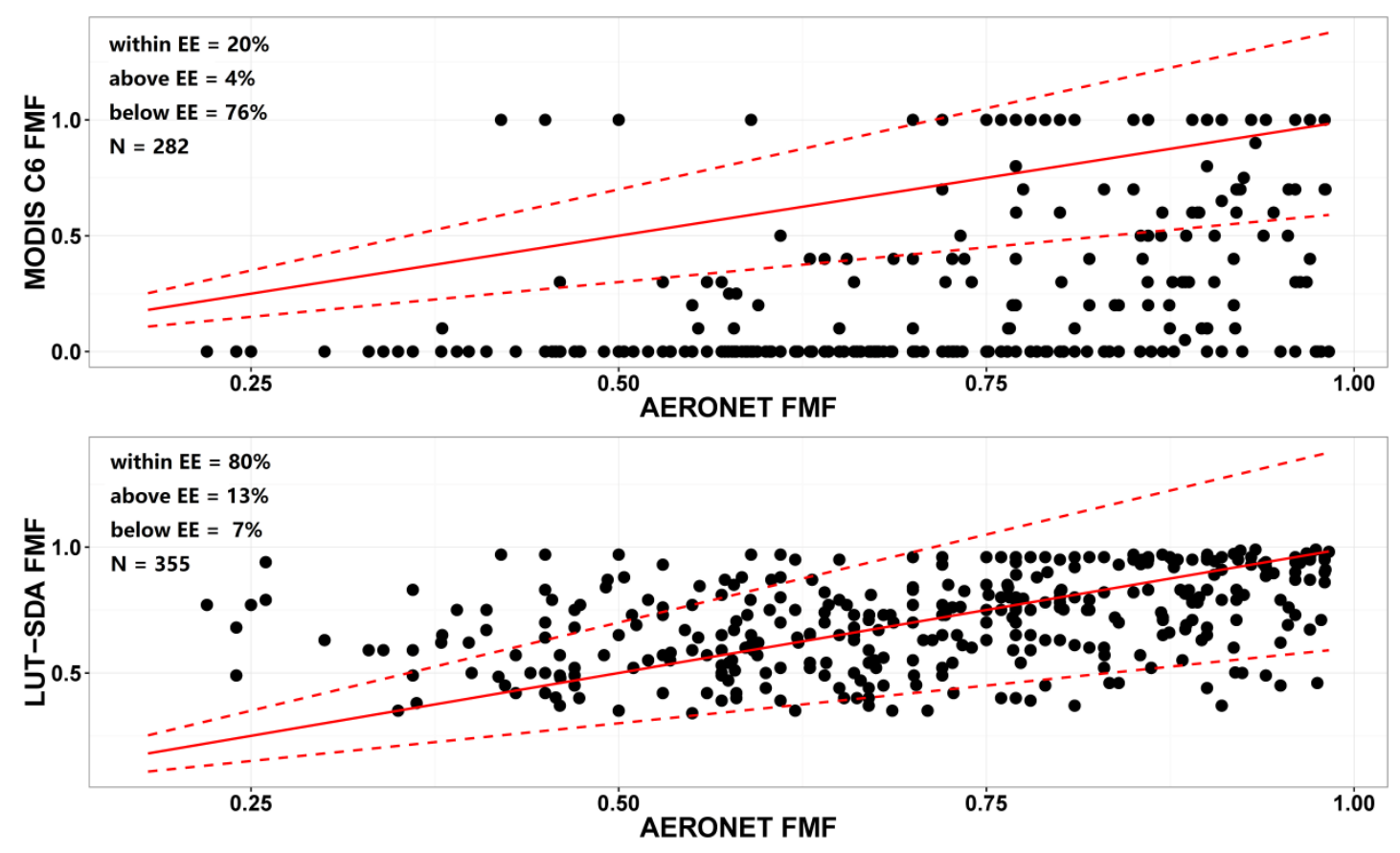

Figure 8. Validation of MODIS C6 and LUT-SDA FMFs against the AERONET FMF. The solid red lines are the 1:1 lines and the dotted red lines are the estimated error envelope lines $( \pm 0.4)$. 
Table 1. RMSEs of the LUT-SDA and MODIS C6 FMFs for different AERONET

stations.

\begin{tabular}{ccc}
\hline AERONET & MODIS C6 FMF & LUT-SDA FMF \\
\hline Beijing & 0.332 & 0.173 \\
CAMS & 0.344 & 0.168 \\
RADI & 0.369 & 0.194 \\
XiangHe & 0.276 & 0.166 \\
PolyU & 0.322 & 0.160 \\
Sheung & 0.422 & 0.152 \\
Osaka & 0.316 & 0.171 \\
Shirahama & 0.328 & 0.175 \\
Noto & 0.349 & 0.153 \\
Mean & 0.340 & 0.168 \\
\hline
\end{tabular}

\subsection{An application to the MODIS SARA AOT}

We applied the LUT-SDA to SARA AOT to take advantage of its higher spatial resolution $(500 \mathrm{~m})$. The LUT-SDA-derived FMF using SARA AOT agrees well with the AERONET FMF (Supplementary Figure S9) and has an RMSE equal to 0.160. Here, we use results from 18 May 2014 to illustrate the difference between the FMFs derived from SARA AOT and MODIS C6 AOT data. Figure 9a and 9b show the spatial distributions of MODIS C6 AOT and SARA-derived AOT, respectively, for the Beijing area. Despite having drastically different resolutions, the gross magnitude and spatial patterns of AOT retrieved by the SARA bear close resemblance to the MODIS C6 AOT, and shows that there was high aerosol loading southeast of Beijing on this date. This area includes the city central region where roads are crowded and the population is dense. In addition, many construction projects, such as a new subway station, are in progress, as described by Yan et al. (2015). There are stark contrasts, however, in the FMF retrieved by the two approaches: many invalid retrievals (zero or 
near zero) across the region for the MODIS C6 retrievals (Figure 9c). This result may not be realistic because a pure coarse-mode $(\mathrm{FMF}=0)$ AOT in an urban area is hardly ever occurs in such a large city area like Beijing. However, the LUT-SDA FMF derived using SARA AOT (Figure 9d) and MODIS C6 AOT (Figure 9e) data show high FMF values (0.6-0.7) in the city of Beijing. The LUT-SDA FMFs based on SARA and MODIS C6 AOT data have a better spatial coverage than the MODIS C6 FMF as well as no extreme values of 0 , which is the expected case for urban areas. A comparison between Figure 9d and Figure 9e suggests that the FMF derived from SARA AOT data provides more detailed information in the urban area shown here than does the MODIS C6 AOT-based FMF, so may be more suitable for urban-scale studies in general.

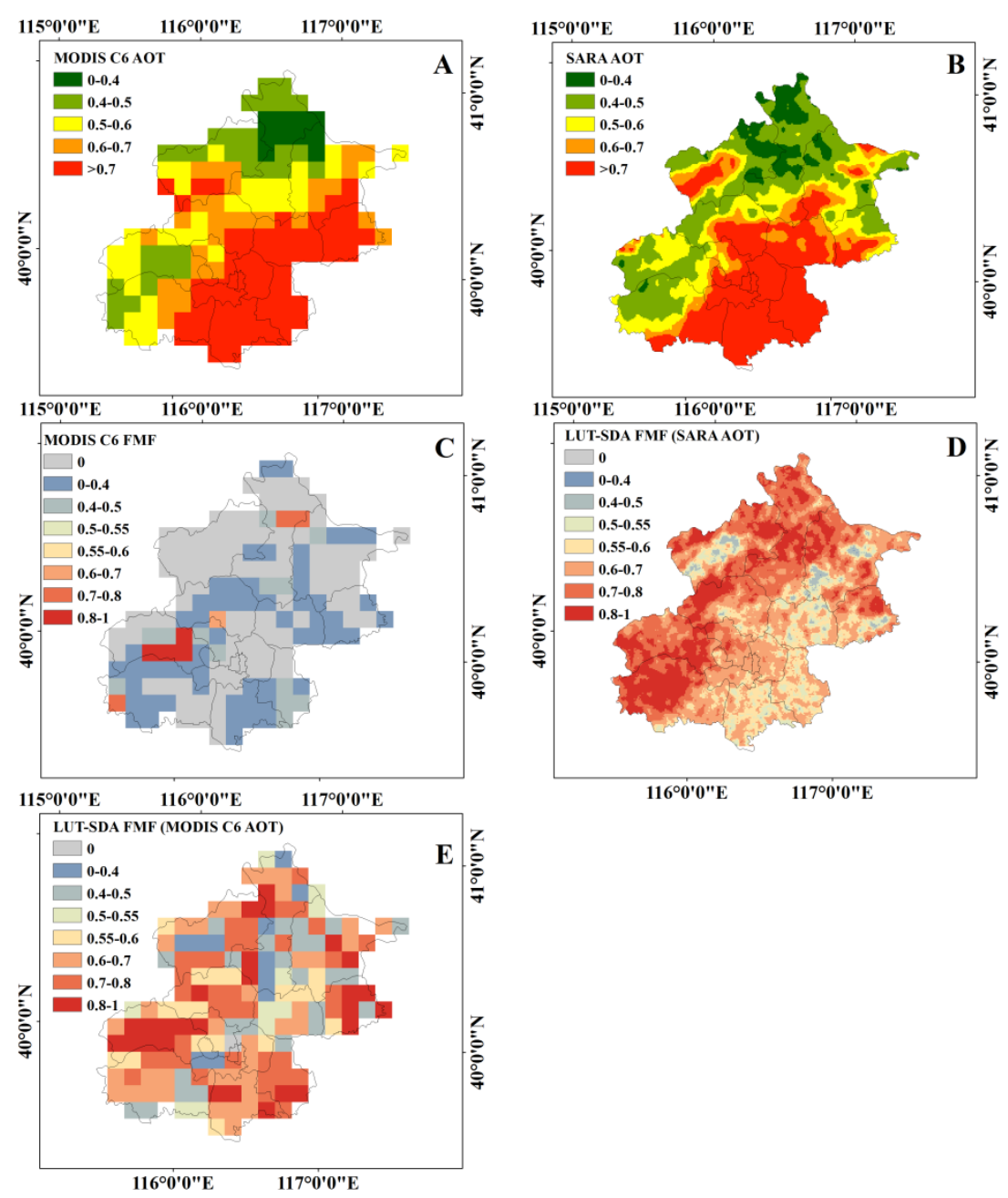

Figure 9. Comparisons of aerosol optical thickness (AOT) and fine-mode fraction (FMF) products: (A) MODIS C6 AOT, (B) SARA AOT, (C) MODIS C6 FMF, (D) 
LUT-SDA FMF derived from SARA AOT data, and (E) LUT-SDA FMF derived from MODIS C6 AOT data for the Beijing urban area.

\subsection{Seasonally-averaged FMF in Beijing}

The spatial distributions of seasonally-averaged FMF retrieved from the SARA AOT $(500 \mathrm{~m})$ are presented in Figure 10. The FMF was 0.6-0.65 over most of Beijing in March-April-May. Such springtime values are generally lower than those in summer (Figure 10c) and winter (Figure 10a). This is because Beijing experiences sand storms originating from western and northern China, e.g., the Mongolian Gobi Desert, in spring (Zhang et al., 2014). These sand storms bring in rich coarse-mode aerosols (dust), resulting in a smaller FMF (Ramachandran, 2007). The FMF is large in summer in Beijing, exceeding 0.75 in most places. In summer, Beijing typically experiences a summer monsoon dominated by heavy convective rainfall that is effective in removing coarse-mode aerosols from the atmosphere, but fine-mode aerosols, including new particles, are readily generated even shortly after rainfall, resulting in a large FMF. The FMF in winter was between 0.65-0.7 in most areas, which suggests the dominance of fine-mode aerosols in winter. This is likely related to heating in winter, when coal combustion increases significantly and enhances the emission of anthropogenic aerosols (Zhao et al., 2014). Figure 10 reveals large FMFs in the urban centre of Beijing where there is always heavy traffic and dense population. In these regions, Ramachandran (2007) reported that fine-mode aerosols are mainly due to gas-to-particle conversion and automobile emissions. To validate the seasonal pattern of the FMF derived by the LUT-SDA, the AERONET FMF for the corresponding period was obtained for comparison. As shown in Figure 11, the AERONET FMF has a similar magnitude and seasonal pattern as those of the LUT-SDA FMF. In both cases, the FMF is higher from June-August than from December-February and March-May. 


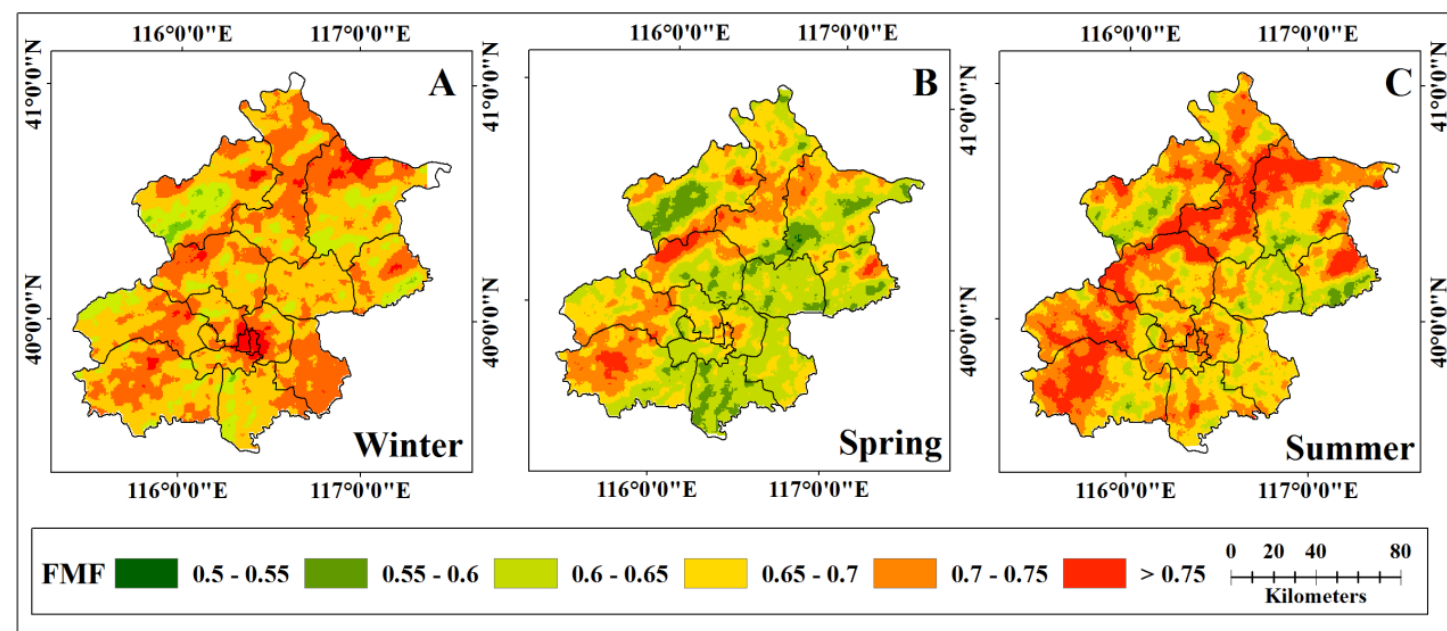

Figure 10. Seasonally-averaged spatial distribution of the fine-mode fraction (FMF) in Beijing retrieved using SARA AOT data: (A) winter (December-February), (B) spring (March-May), and (C) summer (June-August).
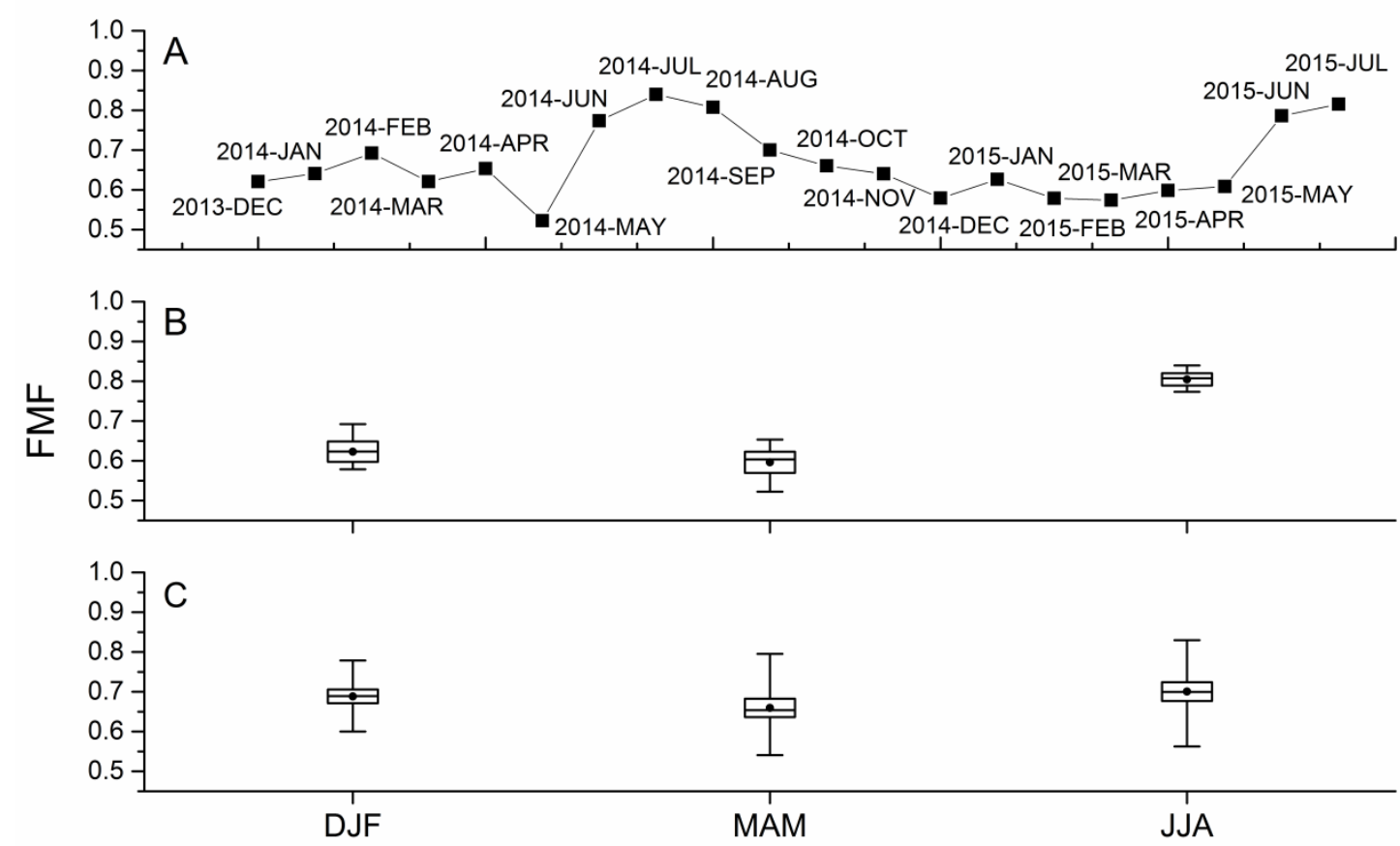

Figure 11. AERONET FMF and satellite-derived FMF using the LUT-SDA for the period of December 2013 to July 2015. A: mean FMF in each month. B: box plots of AERONET FMF in winter (December-February), spring (March-May), and summer (June-August). C: box plots of satellite-derived FMF in winter (December-February), spring (March-May), and summer (June-August).

\subsection{Application of the LUT-SDA to a large area using high-resolution AOT}


Figure 12 shows the spatial distribution of the LUT-SDA-derived FMF (based on SARA AOT data) over northeast China on 16 October 2014 when the region was largely cloud-free. Large values of FMF are seen in the North China Plain, which includes Beijing, Tianjin, and Baoding. The North China Plain is one of the most populated and industrialized areas in China. The rapid development of urbanized construction in this region has led to severe $\mathrm{PM}_{2.5}$ pollution (Quan et al., 2011; Tao et al., 2012). The spatial distribution of FMFs in Figure 12 is similar to that of $\mathrm{PM}_{2.5}$ concentrations reported by Xin et al. (2014). Datong, Shuozhou, and Xinzhou, all located in Shanxi Province, are the other areas with large FMFs (>0.6). Ma et al. (2014) reported that Shanxi Province also experiences high levels of $\mathrm{PM}_{2.5}$ pollution. Figure 12 illustrates that the LUT-SDA with high-resolution AOT as input can be successfully employed for large-scale urban studies. Further studies of the correlation between FMFs and $\mathrm{PM}_{2.5}$ concentrations are required.

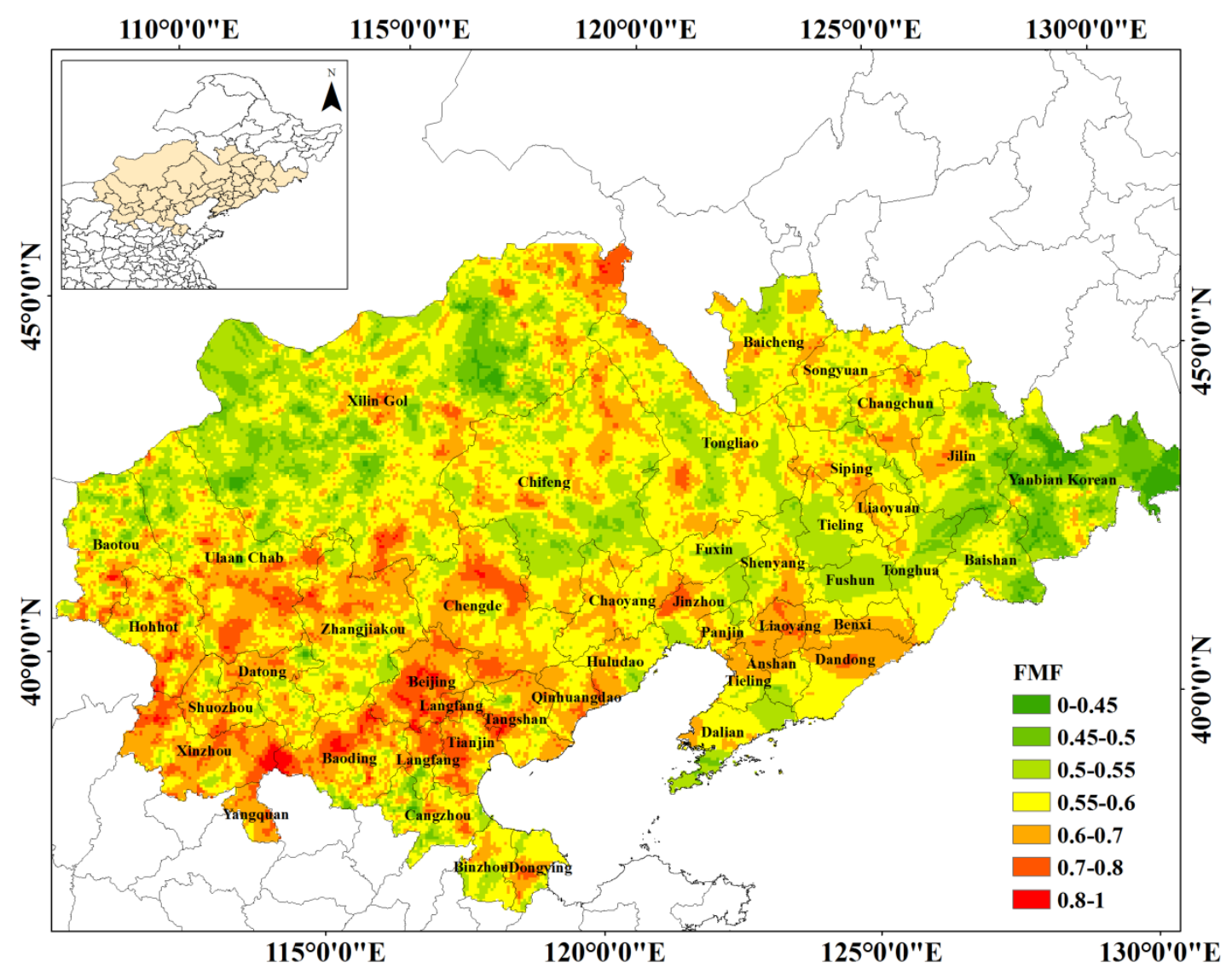

Figure 12. Fine-mode fraction (FMF) retrievals over northeast China on 16 October 
2014.

\subsection{Discussion}

As shown in Figure 2, the biggest difference between the LUT-SDA and the SDA is that the LUT-SDA uses only two parameters (AOT and AE) to calculate the FMF. In Table 1, the RMSE of the LUT-SDA-derived FMF is 0.168, which suggests that a high accuracy in FMF retrievals is still difficult to obtain from satellite images. This is because satellite-based AE retrievals, which provide size information about aerosols, have many uncertainties. As shown in supplementary Figure S10c, the correlation between the MODIS AE and the AERONET AE is 0.34 in this study. Many MODIS $\mathrm{AE}$ data points fall close to $\mathrm{AE}=0.5$, a result also found by Yang et al. (2014). From supplementary Figure S10d, it is clear that when the accuracy of the AE is enhanced, the accuracy of the retrieved FMF is clearly improved. Although the retrieved AOT can have a high precision (supplementary Figure S10a and b), the derived AE is generally less precise. Hasekamp and Landgraf (2007) indicated that uncertainties in the surface reflectance were one of the largest sources of error with regard to aerosol properties retrieved from MODIS. They also found that single-viewing-angle measurements of intensity alone did not provide sufficient information about aerosol properties. Sayer et al. (2013) reported that the latest MODIS C6 "Deep Blue" AOT has a strong correlation with the AERONET AOT $(\mathrm{R}=0.93)$. However, the AE validation had a weaker correlation $(\mathrm{R}=0.45)$. In the latest MODIS C6 aerosol product, the AE over land (based on the DT algorithm) has been removed, therefore users need to derive it themselves (Levy et al., 2013). So to obtain an accurate FMF, a reliable method for retrieving AE needs to be developed. Because MODIS is not a multi-viewing-angle instrument, the use of ground-based data (e.g., AERONET) is a way of improving the FMF retrieval accuracy. Jethva et al. (2010) found that using the new absorbing aerosol model $(\mathrm{SSA}=0.85)$, which is based on AERONET, could improve the retrieval accuracy of FMF over India. 


\section{Conclusions}

This study develops a satellite-based algorithm for retrieving the aerosol fine-mode fraction (FMF) with a particular application to MODIS satellite images in mind. However, the method can be applied to other imagery from multi-wavelength sensors taking measurements in the solar spectral region. It follows the spectral deconvolution algorithm (SDA) first presented by O’Neill (2001) and improved here by building a well-structured look-up table (LUT) with an optimized data range of $\alpha^{\prime}$ for calculating satellite FMFs. The most significant advantage of this method is that it greatly improves the efficiency of FMF retrievals by using aerosol optical thickness (AOT) information at only two wavelengths.

The LUT-SDA was applied to two MODIS AOT products retrieved by two different algorithms: the MODIS C6 dark-target (DT) algorithm (Levy et al., 2007) and the MODIS Aerosol Retrieval Algorithm (SARA) AOT (Bilal et al., 2013). A significant improvement is achieved in retrieving FMF, which is in good agreement with ground-based AERONET data. Using the AERONET FMF as baseline data, the LUT-SDA FMF using MODIS C6 AOT data has a mean root mean square error of 0.168, which is much less than that of the MODIS C6 FMF (0.340). Compared with the MODIS C6 FMF, the LUT-SDA FMF (using MODIS C6 AOT or SARA AOT data) has no extreme values. Using the LUT-SDA with SARA AOT data, the seasonally-averaged FMF in Beijing shows a distinct seasonal pattern, namely, highest in summer and lowest in spring when dust aerosol episodes often influence the region. This finding is in close agreement with the FMF derived from AERONET data.

This study demonstrates that the LUT-SDA is an effective method to derive the FMF using MODIS AOT retrievals. In addition, the LUT-SDA can be further modified and applied to other satellite images, e.g., Landsat or the National Polar-orbiting Partnership (NPP)/Joint Polar Satellite System (JPSS) satellites. 


\section{Acknowledgements}

This study was supported by the Ministry of Science and Technology (2013CB955804), the National Science Foundation of China (91544217), and the National Science Foundation (AGS1534670). We would also like to acknowledge the National Natural Science for Youth Foundation of China (41201404) for their financial support of this research. The authors gratefully acknowledge the MODIS and AERONET teams for their efforts in making the data available. We would like to thank the reviewers for their constructive detailed comments and suggestions related to this paper.

\section{References}

Bellouin N., Boucher O., Haywood J., and Reddy, M. S., 2005. Global estimates of aerosol direct radiative forcing from satellite measurements. Nature, 438, $1138-1141$.

Bilal, M., Nichol, J. E., Bleiweiss, M. P., and Dubois, D., 2013. A Simplified high resolution MODIS Aerosol Retrieval Algorithm (SARA) for use over mixed surfaces. Rem. Sens. Environ., 136, 135-145.

Bilal, M., Nichol, J. E., and Chan, P. W., 2014. Validation and accuracy assessment of a Simplified Aerosol Retrieval Algorithm (SARA) over Beijing under low and high aerosol loadings and dust storms. Rem Sens. Environ., 153, 50-60.

Di Nicolantonio W., Cacciari A., Bolzacchini, E., Ferrero, L., Volta, M., and Pisoni, E., 2007. MODIS aerosol optical properties over north Italy for estimating surface-level PM2.5. Proceedings of Envisat Symposium 2007, Montreux, Switzerland, ESA SP-636.

Diner, D. J., Martonchik, J. V., Kahn, R. A., Pinty, B., Gobron, N., Nelson, D. L., and Holben, B. N., 2005. Using angular and spectral shape similarity constraints to improve MISR aerosol and surface retrievals over land. Remote Sens. Environ., 94, 155-171.

Gasso, S., and O’Neill, N., 2006. Comparison of remote sensing retrievals and in situ measurements of aerosol fine mode fraction during ACE-Asia. Geophys. Res. 
Lett., 33, L05807, doi:10.1029/2005GL024926.

Hasekamp, O. P., and Landgraf, J., 2007. Retrieval of aerosol properties over land surfaces: capabilities of multiple-viewing-angle intensity and polarization measurements. Appl. Opt., 46, 3332-3344.

Hauser, A., Oesch, D., Foppa, N., and Wunderle, S., 2005. NOAA AVHRR derived aerosol optical depth over land. J. Geophys. Res. Atmos., 110, D08204, doi: 10.1029/2004JD005439.

Holben, B. N., Tanré, D., Smirnov, A., Eck, T. F., Slutsker, I., Abuhassan, N., Newcomb, W. W., Schafer, J. S., Chatenet, B., Lavenu, F., Kaufman, Y. J., Castle, J. V., Setzer, A., Markham, B., Clark, D., Frouin, R., Halthore, R., Karneli, A., O'Neill, N.T., Pietras, C., Pinker, R.T., Voss, K., and Zibordi, G., 2001. An emerging ground-based aerosol climatology: Aerosol optical depth from AERONET. J. Geophys. Res. Atmos., 106, $12,067-12,097$.

Jethva, H., Satheesh, S. K., Srinivasan, J., and Levy, R. C., 2010. Improved retrieval of aerosol size-resolved properties from moderate resolution imaging spectroradiometer over India: Role of aerosol model and surface reflectance. $J$. Geophys. Res. Atmos., 115, D18213, doi: 10.1029/2009JD013218.

Kampe, T.U., 2008. Data analysis from remote sensing to better constrain emission an $\mathrm{d}$ transport of carbonaceous aerosol and carbon monoxide resulting from burning processes. Ph.D. thesis, University of Colorado at Boulder, Colorado, U.S.A.

Kaufman, Y. J., Tanre, D., and Boucher, O., 2002. A satellite view of aerosols in the climate system. Nature, 419, 215-223.

Kokhanovsky, A. A., Deuze, J. L., Diner, D. J., Dubovik, O., Ducos, F., Emde, C., Garay, M. J., Grainger, R. G., Heckel, A., Herman, M., Kastsev, I. L., Keller, J., Levy, R., North, P. R. J., Prikhach, A. S., Rozanov, V. V., Sayer, A. M., Ota, Y., Tanre, D., Thomas, G. E., and Zege, E. P., 2010. The inter-comparison of major satellite aerosol retrieval algorithms using simulated intensity and polarization characteristics of reflected light. Atmos.Meas.Tech., 3, 909-932.

Lee, K., and Chung, C. E., 2013. Observationally-constrained estimates of global 
fine-mode AOD. Atmos. Chem. Phys., 13, 2907-2921.

Levy, R. C., Remer, L. A., Mattoo, S., Vermote, E., and Kaufman, Y. J., 2007. Second-generation operational algorithm: Retrieval of aerosol properties over land from inversion of Moderate Resolution Imaging Spectroradiometer spectral reflectance, J. Geophys. Res. Atmos., 112, D13211, doi:10.1029/2006JD007811.

Levy, R. C., Remer, L. A., Kleidman, R. G., Mattoo, S., Ichoku, C., Kahn, R., and Eck, T. F., 2010. Global evaluation of the Collection 5 MODIS dark-target aerosol products over land. Atmos. Chem. Phys., 10, 10,399-10,420.

Levy, R. C., Mattoo, S., Munchak, L. A., Remer, L. A., Sayer, A. M., Patadia, F., and Hsu, N. C., 2013. The Collection 6 MODIS aerosol products over land and ocean. Atmos. Meas. Tech., 6, 2989-3034.

Li, Z., Zhao, X., Kahn, R., Mishchenko, M., Remer, L. A., Lee, K.-H., Wang, M., Laszlo, I., Nakajima, T., and Maring, H., 2009. Uncertainties in satellite remote sensing of aerosols and impact on monitoring its long-term trend: a review and perspective, Ann. Geophys., 27, 1-16.

Luo, N., Wong, M. S., Zhao, W., Yan, X., and Xiao, F., 2015. Improved aerosol retrieval algorithm using Landsat images and its application for PM10 monitoring over urban areas. Atmos. Res., 153, 264275.

Ma, Z., Hu, X., Huang, L., Bi, J., and Liu, Y., 2014. Estimating ground-level PM2.5 in China using satellite remote sensing. Environ. Sci. Tech., 48, 7436-7444.

Mishchenko, M. I., and Geogdzhayev, I. V., 2007. Satellite remote sensing reveals regional tropospheric aerosol trends. Optics Express, 15, 7423-7438.

Munchak, L. A., Levy, R. C., Mattoo, S., Remer, L. A., Holben, B. N., Schafer, J. S., Hostetler, C. A., and Ferrare, R. A., 2013. MODIS $3 \mathrm{~km}$ aerosol product: applications over land in an urban/suburban region. Atmos. Meas. Tech., 6, $1747-1759$

O'Neill, N. T., 2010. Comment on "Classification of aerosol properties derived from AERONET direct sun data" by Gobbi et al. (2007). Atmos. Chem. Phys., 10, 10017-10019.

O’Neill, N. T., Dubovik, O., and Eck, T. F., 2001. Modified Angstrom exponent for 
the characterization of submicrometer aerosols. Appl. Optics, 40, 2368-2375.

O’Neill, N. T., Eck, T. F., Smirnov, A., Holben, B. N., and Thulasiraman S., 2003. Spectral discrimination of coarse and fine mode optical depth. J. Geophys. Res. Atmos., 108, D17, doi:10.1029/2002JD002975.

Pope, C. A., III, Burnett, R. T., Thun, M. J., Calle, E. E., Krewski, D., Ito, K. et al., 2002. Lung cancer, cardiopulmonary mortality, and long-term exposure to fine particulate air pollution. J. Am. Med. Assoc., 287, doi:10.1001/jama.287.9.1132.

Quan, J., Zhang, Q., He, H., Liu, J., Huang, M., and Jin, H., 2011. Analysis of the formation of fog and haze in North China Plain (NCP). Atmos. Chem. Phys., 11, 8205-8214.

Ramachandran, S., 2007. Aerosol optical depth and fine mode fraction variations deduced from Moderate Resolution Imaging Spectroradiometer (MODIS) over four urban areas in India. J. Geophys. Res. Atmos., 112, D16207, doi:10.1029/2007JD008500.

Ramanathan, V., et al., 2007. Warming trends in Asia amplified by brown cloud solar absorption. Nature, 448, 575-578.

Remer, L. A., Mattoo, S., Levy, R. C., Munchak, L. A., 2013. MODIS 3 km aerosol product: algorithm and global perspective. Atmos. Meas. Tech., 6, 1829-1844.

Sasaki, K., and Sakamoto, K., 2005. Vertical differences in the composition of PM10 and PM2.5 in the urban atmosphere of Osaka, Japan. Atmos. Environ., 39, $7240-7250$.

Sayer, A. M., Hsu, N. C., Bettenhausen, C., and Jeong, M.-J., 2013. Validation and uncertainty estimates for MODIS collection 6 "deep blue" aerosol data. $J$. Geophys. Res. Atmos., 118, 7864-7873.

Soni K., Singh, S., Bano, T., Tanwar, R.S., and Nath, S., 2011. Wavelength dependence of the aerosol Angstrom exponent and its implications over Delhi, India. Aerosol Sci. Tech., 45, 1488-1498.

Tao, M., Chen, L., Su, L., and Tao, J., 2012. Satellite observation of regional haze pollution over the North China Plain. J. Geophys. Res. Atmos., 117, D12, doi: 10.1029/2012JD017915. 
Wong, M. S., Nichol, J. E., and Lee, K.-H., 2011. An operational MODIS aerosol retrieval algorithm at high spatial resolution, and its application over a complex urban region. Atmos. Res., 99, 579-589.

Xin, J., Zhang, Q., Wang, L., Gong, C., Wang, Y., Liu, Z., and Gao, W., 2014. The empirical relationship between the PM2.5 concentration and aerosol optical depth over the background of North China from 2009 to 2011. Atmos. Res., 138, $179-188$.

Yan, X., Shi, W., Zhao, W., and Luo, N., 2015. Mapping dustfall distribution in urban areas using remote sensing and ground spectral data. Sci. Total Environ., 506-507, $604-612$.

Yan X., Shi, W., Luo, N., Zhao, W., 2016. A new method of satellite-based haze aerosol monitoring over the North China Plain and a comparison with MODIS Collection 6 aerosol products. Atmos. Res., 171, 31-40.

Yang, L., Xue, Y., Guang, J., Kazemian, H., Zhang, J., Li, C., 2014. Improved aerosol optical depth and Angstrom exponent retrieval over land from MODIS based on the Non-Lambertian forward model. IEEE Geosci. Remote., 11, 1629-1633.

Zha, Y., Wang, Q., Yuan, J., Gao, Y., Jiang, J. J., Lu, H., and Huang, J., 2011. Improved retrieval of aerosol optical thickness from MODIS measurements through derived surface reflectance over Nanjing, China. Tellus, 58B, 952-958.

Zhang, Y., and Li, Z., 2013. Estimation of PM2.5 from fine-mode aerosol optical depth. J. Rem. Sens., 17, 929-943.

Zhang, Y., and Li, Z., 2015. Remote sensing of atmospheric fine particulate matter (PM2.5) mass concentration near the ground from satellite observation. Rem. Sens. Environ., 160, 252-262.

Zhang, Z., Wang, H., Zhang, L., Hu, D., Tian, P., Liang, J., and Wang, S., 2014. Analysis and comparison of the aerosol microphysical properties at three AERONET sites in China. China Environ. Sci., 34, 1927-1937.

Zhao, C., Wang, Y., Wang, Y., Zhang, H., and Zhao, B., 2014. Temporal and spatial distribution of PM2.5 and PM10 pollution status and the correlation of particulate matters and meteorological factors during winter and spring in 
Beijing. Environ. Sci., 35, 418-427.

\section{LIST OF FIGURE CAPTIONS}

Figure 1. The Beijing, Hong Kong, and Osaka study areas (outlined in red). The locations of the nine AERONET sites used in the study are: Beijing $\left(39.98^{\circ} \mathrm{N}\right.$, $\left.116.38^{\circ} \mathrm{E}\right)$, CAMS $\left(39.93^{\circ} \mathrm{N}, 116.32^{\circ} \mathrm{E}\right)$, RADI $\left(40.01^{\circ} \mathrm{N}, 116.38^{\circ} \mathrm{E}\right), \mathrm{XiangHe}$ $\left(39.75^{\circ} \mathrm{N}, 116.96^{\circ} \mathrm{E}\right)$, Noto $\left(37.33^{\circ} \mathrm{N}, 137.14^{\circ} \mathrm{E}\right)$, Osaka $\left(34.65^{\circ} \mathrm{N}, 135.59^{\circ} \mathrm{E}\right)$, Shirahama $\left(33.69^{\circ} \mathrm{N}, 135.36^{\circ} \mathrm{E}\right)$, Hong_Kong_Polyu $\left(22.30^{\circ} \mathrm{N}, 114.18^{\circ} \mathrm{E}\right)$, and Hong_Kong_Sheung $\left(22.48^{\circ} \mathrm{N}, 114.12^{\circ} \mathrm{E}\right)$.

Figure 2. Flowchart describing the SDA and the LUT-SDA.

Figure 3. The look-up table used in the LUT-SDA. The blue points are test data from AERONET.

Figure 4. Histograms of $\alpha^{\prime}$ from four years (2009 to 2012) for Beijing, Hong Kong, and Osaka.

Figure 5. Comparisons of the LUT-SDA-derived FMF (in black) and the AERONET FMF (in red) from January to June 2013 in Beijing, Osaka, and Hong Kong.

Figure 6. Correlation between the FMF and $\alpha^{\prime}$ errors. The red line is the best-fit line through the data points.

Figure 7. Spatial distributions of the LUT-SDA FMF (left column) and the MODIS C6 FMF (right column) for Beijing (top row), Osaka (middle row), and Hong Kong (bottom row).

Figure 8. Validation of MODIS C6 and LUT-SDA FMFs against the AERONET FMF. The solid red lines are the 1:1 lines and the dotted red lines are the estimated 
error envelope lines $( \pm 0.4)$.

Figure 9. Comparisons of aerosol optical thickness (AOT) and fine-mode fraction (FMF) products: (A) MODIS C6 AOT, (B) SARA AOT, (C) MODIS C6 FMF, (D) LUT-SDA FMF derived from SARA AOT data, and (E) LUT-SDA FMF derived from MODIS C6 AOT data for the Beijing urban area.

Figure 10. Seasonally-averaged spatial distribution of the fine-mode fraction (FMF) in Beijing retrieved using SARA AOT data: (A) winter (December-February), (B) spring (March-May), and (C) summer (June-August).

Figure 11. AERONET FMF and satellite-derived FMF using the LUT-SDA for the period of December 2013 to July 2015. A: mean FMF in each month. B: box plots of AERONET FMF in winter (December-February), spring (March-May), and summer (June-August). C: box plots of satellite-derived FMF in winter (December-February), spring (March-May), and summer (June-August).

Figure 12. Fine-mode fraction (FMF) retrievals over northeast China on 16 October 2014. 